\title{
Fugindo da escola do passado: arte na vida
}

\section{Escaping from the school of the past: art within life}

Lucia Gouvêa Pimentel ${ }^{1}$

Universidade Federal de Minas Gerais

\section{Resumo}

Repensar a aprendizagem em Arte na contemporaneidade implica revisitar tempos passados, repensá-los, buscando compreender quais seus contextos e heranças, com vistas a melhor entender o contexto contemporâneo e identificar as possibilidades de atuação educativa em Arte. A partir das ambiências presentes, na atualidade, no contexto das artes e do que se considera ser o campo da educação, são levantados pontos de discussão para que se considere a importância do ensino/aprendizagem de Arte na ambiência escolar.
\end{abstract}

Palavras chave

Aprendizagem em Arte, ambiência artística, Arte/Educação contemporânea.

\begin{abstract}
Rethinking learning in the Arts in contemporaneity implies revisiting and rethinking the past, seeking to understand its contexts and legacies in order to better understand the contemporary context and identify the educational potential of Art. On the basis of current ambiances in the field of Art and in what is considered as the field of Education, this paper raises issues of discussion so that the importance of Art teaching and learning in school contexts are considered.
\end{abstract}

Keywords

Learning in the Arts, artistic ambience, contemporary Art/Education.

Na escola são combinadas coisas entre os homens. Isto acarreta paz, na medida em que há um senso comum, gerido com absoluta evidência pelo bom senso, e nos vem daí a segurança de que ninguém ensinará que $2+2=5$. Ao contrário, qualquer tentativa de se questionar a igualdade $2+2=4$ será respondida à altura pela Escola,

que dentre tantos castigos possíveis obrigará o infrator a encher mil páginas de caderno com todas as igualdades aprovadas. Aos professores, missionários do Saber, caberá a sagrada tarefa da transmissão do Bem comum e Útil a todas as comunidades. Nilma Gonçalves Lacerda

\section{Tempos passados}

O século XX é tido como o de grandes transformações nas artes, nas ciências, nas tecnologias, na vida. O Modernismo incita a autonomia da arte que não quer mais ter estilos fixos, onde os artistas se enquadram. O quadro, ele mesmo, antes tão exaltado, dá lugar a outros contornos, já não consegue mais conter a totalidade da obra. O limite

Revista Digital do LAV - Santa Maria - vol. 8, n. 2, p. 5 - 17. - mai./ago. 2015 ISSN 1983 - 7348 http://dx.doi.org/10.5902/1983734819862 
se esgarça e há fusão de técnicas, materiais, suportes, formas, espaços, ideias e movimentos.

A década de 1960 é considerada, por alguns autores ${ }^{1}$, um marco na modernização internacionalizante. Buscava-se uma dinâmica cultural mais politizada e mais próxima do perfil nacionalista e das lutas sociais emergentes. Isso se nota mais em Cinema, Música e Teatro, principalmente. Pode-se dizer que as Artes Visuais ficaram mais à margem das mobilizações pois a preocupação dirigiu-se a garantir posição de estabilidade e valor garantido no mercado, considerando-se as tendências abstracionistas, do concretismo e do neoconcretismo. Surgem os marchands, instalam-se galerias com vernissages como eventos sociais e culturais. Embora buscando a internacionalização, Bulhões (2014) constata que a maioria das obras desse período ficaram no Brasil, pois, na época, a classe dominante pagava altos preços por elas. Isso fez com que o mercado da arte fosse direcionado basicamente para a formação de consumidores nacionais.

Uma outra vertente liga-se à ampliação e, ao mesmo tempo, especialização do mercado, que passou a abranger "diferentes produções destinadas a diversos tipos de público, capazes de se tornarem consumidores." (BULHÕES, 2014, p.37.). No entanto, o processo de difusão saiu praticamente das mãos do artista, ficando por conta dos meios de comunicação e das propagandas das instituições que divulgavam as informações dos objetos e eventos artísticos. Arte passa a ser considerada um componente do status social, mais que do capital cultural.

A comercialização de artes visuais, principalmente a partir da década de 1970, reforça a separação entre o que é arte e o que não é arte, com fins de manter processos de experimentação intelectualizados e herméticos em alta, desarticulando iniciativas democratizantes mais populares. A separação entre artista e público - com uma vanguarda que exigia, para a apreciação de sua obra, uma formação que a população em geral não tinha e não encontrava à sua disposição -, a consolidação do poder das instâncias de difusão e o reforço, pelo mercado, do elitismo em Artes Visuais foram também responsáveis pelo abismo criado entre escola e arte. Pode-se dizer que, em Artes Visuais, no início, o Estado autoritário apoiou, de forma sorrateira, o sistema da arte, por intermédio da censura e do financiamento a projetos de seu interesse. Uma vez consolidada a forma elitista de tratamento às Artes Visuais, no entanto, foi o próprio

\footnotetext{
${ }^{1}$ Entre eles, Bulhões (2014).
}

Revista Digital do LAV - Santa Maria - vol. 8, n. 2, p. 5 - 17. - mai./ago. 2015 ISSN 1983 - 7348 http://dx.doi.org/10.5902/1983734819862 
sistema da arte que fez censura às produções de cunho social, não sendo mais necessária a interveniência da ditadura.

Objetos que no passado foram válidos e significativos, por seu lugar na vida de uma comunidade, funcionam hoje isolados das condições de sua origem. Em vista disso, são também desvinculados da experiência comum e servem de insígnias de bom gosto e atestados de uma cultura especial. (DEWEY, 2010, p.68-69)

Artistas descontentes com a elitização da arte, reordenam seus ateliês e suas produções - que devem "falar" por si -, ou negam-se a serem "tradicionais". Clamam pela participação do espectador, de suas ações corpóreas, do diálogo ou da intromissão na obra. Isso acarreta que também os espectadores devam se transformar em fruidores, integralizar a obra com seus pensamentos e/ou ações sobre ela.

Os manipuladores de mídia, considerando que as pessoas em geral não conseguiriam alcançar o entendimento das obras em exposição, formulam regras para orientá-las a seguirem por um caminho supostamente "correto":

Primeiro veja a forma, depois a composição, depois analise os
elementos, depois pense no que essa obra lhe faz lembrar, depois
nomeie-a a seu gosto e, por fim, faça uma obra o mais possível
parecida com a do artista. Ah! E o artista quis dizer "isto". Você
consegue perceber?

Isto é feito, também, na escola, com reproduções de obras - na maioria das vezes reproduções fotográficas impressas sem boa qualidade e sem relação com a modalidade ou as dimensões das obras originais.

Mas os fruidores resistem. Tentam, a seu modo, entender o que se passa com as Artes Visuais. A ideia de que "tudo é arte" e "isso eu também faço" toma mais espaço que a discussão sobre as questões intrínsecas da arte contemporânea e sua relação com a vida.

A tecnologia avança e invade a vida, é apropriada por ela que, por sua vez, se apropria da vida. E a arte se apresenta enquanto possibilitadora tanto dos fenômenos objetivos quanto de compartilhamentos pessoais, individuais, subjetivos. A experiência artística é essencial tanto ao artista quanto ao fruidor, em todas as suas dimensões. O que muda para cada um são as condições de pensar arte em suas possíveis entradas, entrecruzamentos, afecções e saídas.

Revista Digital do LAV - Santa Maria - vol. 8, n. 2, p. 5 - 17. - mai./ago. 2015 ISSN 1983 - 7348 http://dx.doi.org/10.5902/1983734819862 
Ao propiciar interação e integração artista-obra-fruidor, a exigência corpórea para um mais que para outro, às vezes - também é modificada: os sentidos, a imaginação e as relações corporais tendem a se expandir para que a arte aconteça.

Com o pluralismo das Artes Visuais, entra em cena um outro profissional: o "curador contemporâneo" (RUPP, 2014, p.78). Este é menos enfático na abordagem do fruidor, preocupando-se em identificar tendências e temáticas emergentes e organizar exposições de modo que sejam mais "entendíveis" pelo fruidor. Também há, em muitos casos, a preocupação com o que será feito em mediação, quando o espaço expositivo possui equipe de Arte/Educação. Neste caso, o curador pode entrar em contato com a equipe responsável tanto pela elaboração do material educativo quanto pela equipe que fara a mediação junto ao público. Nas palavras de Rupp (2014, p.77), "a expansão de locais expositivos fomentou o estabelecimento do curador de exposições, que, além de agir como crítico, também passou a atuar de forma mais ativa em conjunto com os artistas, pensando a exposição como um todo: conceito, criação, execução e montagem".

\section{O currículo de Arte $^{2}$ no século $X^{3}$}

Nossa história social é perpassada pelas influências estrangeiras e pela miscigenação. $O$ currículo, como ação social, também participa dessa história, tanto em miscigenação quanto nas influências hegemônicas, principalmente europeia e norte-americana.

Moreira (1995) indica que no início da organização de reformas educacionais de alguns estados brasileiros o que havia eram tradições fundamentadas em uma base filosófica híbrida, com princípios de Herbart, de Pestalozzi e dos jesuítas. ${ }^{4}$

Segundo Barbosa (1978, p.11), "o século XIX, especialmente a década de 1870, foi o período da História da educação Brasileira em que a preocupação com o ensino da Arte (concebida como Desenho) se nos apresenta como mais extensa e mais aprofundada".

\footnotetext{
${ }^{2}$ Coloca-se a denominação do componente curricular oficial a partir da LDB9394/06 - Arte - devendo ser consideradas aqui o que acontecia no currículo escolas com as outras denominações havidas.

${ }^{3}$ Informações com mais detalhes em PIMENTEL (1999; 2014).

${ }^{4}$ MOREIRA (1995) adverte que todos estes pontos são bem sumarizados por FIGUEIREDO (1981), em seu estudo sobre tendências curriculares no Brasil que, segundo ela, podem ser caracterizadas por: a) ênfase em disciplinas literárias e acadêmicas; b) enciclopedismo; e c) divisão entre trabalho manual e intelectual.
}

Revista Digital do LAV - Santa Maria - vol. 8, n. 2, p. 5 - 17. - mai./ago. 2015 ISSN 1983 - 7348 http://dx.doi.org/10.5902/1983734819862 
O ensino de arte, no Brasil, foi organizado primeiramente no ensino superior. $\mathrm{Na}$ educação básica, a implantação de Arte no currículo baseia-se nas ideias de Rui Barbosa, a partir do ideário positivista da segunda metade do século XIX. O desenho, concebido como linguagem técnica e linguagem da ciência, era o argumento usado para demonstrar a importância do ensino de Arte. Já a partir da Semana de Arte Moderna de 1922, a valorização do desenho como técnica e a exaltação dos elementos internos formais expressivos são as duas tendências no ensino de Arte mais relevantes.

Na primeira metade do século $X X$, alternam-se reformas educacionais que consideram o Estado como responsável pela orientação didática e administrativa (1901-1910; 19151925) e a que advoga a autonomia em relação à fiscalização do governo e à uniformidade de programas, ficando a cargo de cada instituição de ensino formular e aprovar seu próprio programa (1911 - 1915).

Na década de 1920, notadamente Bahia, Minas Gerais e o antigo Distrito Federal efetuam reformas educacionais. Na Bahia destaca-se Anísio Teixeira, com o foco de que as disciplinas devem ser consideradas instrumentos para o alcance de determinados fins, não como fim em si mesmas.

Em Minas Gerais destacam-se Francisco Campos e Mário Casassanta, com os princípios da Escola Nova, de tendência à abordagem técnica, mas também considerando a escola tanto como refletora da sociedade, como instrumento de reconstrução social. Percebe-se a utilização de princípios definidos de elaboração de currículos e programas: preocupação em desenvolver na criança habilidades de observar, pensar, julgar, criar, decidir e agir, com a qualidade do conhecimento a ser construído - usando o método de centro de interesses de Decroly -, e com atividades tais como visitas, excursões, organização de museus e clubes escolares, bibliotecas etc.

A reforma elaborada em 1927 por Fernando de Azevedo, no antigo Distrito Federal, enfatizou as tarefas sociais do sistema escolar, preocupando-se em renovar o currículo e modernizar métodos e estratégias de ensino e de avaliação, insistindo na democratização da sala de aula e na relação professor-aluno. No entanto, apesar de denotar preocupação com a reconstrução social, sua contribuição ficou restrita a indicar novas possibilidades de métodos e técnicas.

Revista Digital do LAV - Santa Maria - vol. 8, n. 2, p. 5 - 17. - mai./ago. 2015 ISSN 1983 - 7348 http://dx.doi.org/10.5902/1983734819862 
Na década de 1930, a ênfase voltou-se para a postura conservadora. A Reforma Campos, liderada por Francisco Campos, indicava currículos e programas rigidamente prescritos, com um sistema centralizado e instrumentos controladores, com inspetores federais encarregados de inspecionar e controlar diretores, sendo reforçada a importância dos especialistas educacionais. Observa-se, portanto, um retrocesso em relação às conquistas anteriores.

Após a Segunda Guerra Mundial, o ensino da Arte continua com as discussões entre o desenho como arte e o desenho como técnica, entre a expressão do eu e a expressão dos materiais (BARBOSA, 1978, p.115). No Brasil, nos cursos de treinamento dos primeiros especialistas em currículo este estava mais associado aos supervisores de ensino que aos professores.

Na década de 1950, a influência americana aumentou significativamente. Supervisores e professores foram treinados a produzir, adaptar e distribuir materiais didáticos a serem usados no treinamento de professores, a fim de capacitá-los a executar o currículo. Supervisores eram treinados para melhor controlar o professor e o processo curricular. Embora a intenção declarada fosse de atender o mundo moderno e a coesão social, o que aconteceu foi a descontextualização do currículo, que passou a ser tratado como um conjunto de técnicas científicas.

O início da década de 1960 é caracterizado pela ambiguidade: a busca de modelos estrangeiros e, ao mesmo tempo, a preocupação com a eficiência e o planejamento, experiências individuais e questões sociais. (MOREIRA, 1995). Havia, por parte de educadores, preocupação com a autonomia cultural do país e com o papel da educação em seu processo. Paulo Freire propôs, nessa época, a pedagogia crítica, em que as questões sociais fossem analisadas a partir de uma abordagem sociológica. É a primeira tentativa, no Brasil, de considerar currículo e conhecimento com intenção emancipadora. Nos anos 1970, fica clara a tendência tecnicista, demonstrada pela divisão do trabalho didático em: objetivos, conteúdos, métodos e avaliação. O trabalho pedagógico é fragmentado para tornar o sistema educacional efetivo e produtivo, e o currículo continua sendo indicado para a socialização, mas não para a emancipação. É implantada a Educação Artística, de cunho superficialista; Arte é vista somente como lazer, relaxamento, sendo ignorada como área de conhecimento. Sua base são as ideias de

Revista Digital do LAV - Santa Maria - vol. 8, n. 2, p. 5 - 17. - mai./ago. 2015 ISSN 1983 - 7348 http://dx.doi.org/10.5902/1983734819862 
Lowenfeld e Read, que são lidos sem posicionamento crítico e não em sua originalidade, levando a maioria das escolas ao espontaneísmo (laissez faire).

Nos anos 1980, buscou-se desvalorizar os modelos associados aos governos militares e uma orientação mais autônoma. Tanto o terceiro Plano Setorial de Educação, Cultura e Esportes, de 1980, quanto o documento Educação para Todos (1985) reafirmam a importância e a necessidade de alfabetizar as massas, e o currículo é o principal instrumento de tal processo. Como reação ao descaso com que o ensino de Arte era tratado, os arte-educadores reforçaram seu movimento em prol de mudanças na área. Foram realizados vários congressos, seminários e encontros, e divulgados manifestos. Foram criadas as associações estaduais de arte/educadores e, posteriormente, a Federação de Arte-Educadores do Brasil (FAEB).

Nos anos 1990 aconteceram as discussões sobre a nova Lei de Diretrizes e Bases da Educação Nacional - LDB 9394/96, que foi promulgada em dezembro de 1996. Foi extinguida a Educação Artística e instituída a disciplina Arte. Em 1997 foram divulgados os Parâmetros Curriculares Nacionais (PCN) - Arte, indicando que cada modalidade artística deveria ter professor especialista, extinguindo, no documento, a polivalência.

Na primeira década dos anos 2000, adendos importantes foram feitos à LDB 9394/96 e tentou-se implantar os PCN, mas as próprias secretarias de Educação dos estados e municípios insistem na polivalência, por questões políticas, mantendo concursos públicos para Professor de Arte (quando acontecem) com a característica de Educação Artística. Na maioria das vezes, essa configuração perdura até hoje, em 2015, com editais em que o candidato tem que estudar e fazer prova em que constam conteúdos de Artes Visuais e Audiovisuais, Dança, Música e Teatro. É notório o descompasso entre a formação especializada exigida e o descumprimento da exigência pelo próprio poder público que a instituiu.

Assim, verifica-se que o pensamento curricular brasileiro sofre "efeitos de interação de condições internacionais, societárias e processuais" (MOREIRA, 1995, p. 197), com variações de influências, pressionando e limitando o desenvolvimento de ações indentitárias educacionais brasileiras.

Revista Digital do LAV - Santa Maria - vol. 8, n. 2, p. 5 - 17. - mai./ago. 2015 ISSN 1983 - 7348 http://dx.doi.org/10.5902/1983734819862 
Pode-se detectar, também, que boa parte dos profissionais da educação não se submete a simplesmente executar programas e responde à imposição não somente com críticas, mas com projetos e reflexões registradas, visando à sedimentação de um pensamento educacional brasileiro. No entanto, não se conseguiu ainda a infiltração necessária para que Arte seja respeitada como área de conhecimento e componente curricular de fundamental importância na formação de crianças, jovens e adultos em situação de escolaridade.

\section{Ambiência artística e ambiência educacional}

A construção de conhecimento implica em ação relacional e intencional do sujeito com informações. Os conhecimentos são construídos socialmente, mas dependem de um movimento interno do sujeito. Nesse sentido, é importante salientar as condições em que o processo escolar tem condições de possibilitar a construção de conhecimentos em Arte na contemporaneidade.

A primeira instância a ser considerada é a ambiência em que o ensino/aprendizagem de Arte está inserido. Define-se ambiência como sendo o conjunto de fatores físicos e intelectuais que interferem nas ações de seus componentes. É o "lugar" onde se pode estruturar, desenvolver e expressar ideias e pensamentos. É o que se tem de mais próximo como campo de ação. A ambiência faz parte de campos de ação mais amplos, os ecossistemas, que podem ser considerados como espaços de interação interdependentes, em que todos os elementos precisam estar "vivos" e atuantes, pois a "morte" de qualquer um acarreta desacertos severos nos demais, podendo causar uma derrocada em cadeia. Quando algo acontece, é preciso buscar uma nova configuração para que os impactos sejam minimizados e as ações continuem a ser possíveis.

De forma geral, considera-se os ecossistemas culturais como os mais acercam-se do ensino/aprendizagem em Arte. As ações precípuas das artes, por sua vez, estão inseridas nos ecossistemas estéticos e nos ecossistemas artísticos, bem como as de ensino/aprendizagem estão inseridas nos ecossistemas educacionais. Esses três ecossistemas estão inseridos nos ecossistemas culturais, nutrem-se deles ao mesmo tempo que os nutrem.

Nos ecossistemas culturais tem-se os conhecimentos construídos a partir de outras áreas do conhecimento que possibilitam interface com a cultura. Para Viveiros de Castro (2002. p.298), cultura são os "conteúdos afetivos e cognitivos da vida do grupo: do conjunto de

Revista Digital do LAV - Santa Maria - vol. 8, n. 2, p. 5 - 17. - mai./ago. 2015 ISSN 1983 - 7348 http://dx.doi.org/10.5902/1983734819862 
disposições e capacidades inculcadas em seus membros através de meios simbólicos variados, bem como os conceitos de práticas que conferem ordem, significação e valor à totalidade do existente". Assim, pode-se dizer que a base social é tecida em rede pelo homem com os sentidos que ele atribui e preserva, ficando nela imerso.

Inseridos nos ecossistemas culturais estão, entre outros, os ecossistemas estéticos, que comportam interdependências e intervenções mútuas entre as artes e os demais universos em que estética é componente essencial ou conjuntural.

Nos ecossistemas artísticos os conhecimentos são construídos a partir da área de Artes, em sua diversidade. "Ecossistemas artísticos podem ser pensados como processos, dinâmicas, mobilidades, equilíbrios precários, organicidades tênues; inteligências em constante estado de adaptabilidade, conluios do aleatório com o intencional, demo/grafias artísticas, ecoartísticas." (SOUZA, J.A.M.; PIMENTEL, L.G., 2014)

Os ecossistemas educacionais abarcam ações relacionadas ao comportamento humano como fator de integração social e cognitiva. A partir dos ecossistemas próprios da arte e da natureza específica de seus meios, há que se lançar novas provocações sobre os saberes que permeiam os ecossistemas estéticos e educacionais, de modo que história, filosofia, sociologia, antropologia etc. não sejam somente aplicadas ao ensino/aprendizagem em arte, mas se vejam implicadas nele.

Em relação à ambiência artística/educacional para o ensino/aprendizagem de Arte, temse que estão imbricados elementos de herança cultural radicalizados e elementos inéditos, que se reconfiguram constantemente, tanto em relação à arte quanto em relação à educação.

Constata-se que o que é herança cultural enraizada tem seu lugar constante na maioria das escolas; no entanto, os elementos inéditos são motivo de resistência e necessitam de ações mais ousadas para que possam ser respeitadas e incorporadas na prática educativa institucional. Talvez o currículo seja o elemento da ambiência que mais tenha sido foco de estudos, pesquisas e propostas, mas também seja o de mais difícil atualização e dinamização. Pensar currículo não como uma lista de conteúdos a serem despejados nos alunos, mas como possibilidade de construção de conhecimentos

Revista Digital do LAV - Santa Maria - vol. 8, n. 2, p. 5 - 17. - mai./ago. 2015 ISSN 1983 - 7348 http://dx.doi.org/10.5902/1983734819862 
significativos para a vida é o grande desafio do ensino/aprendizagem de arte na contemporaneidade.

\section{Tentativa de fuga}

Considerando-se o currículo como um artefato cultural e social, em que as relações de poder estão implícitas, e que ele atende a prioridades sociopolíticas datadas, sofrendo intercorrências internacionais, societárias e processuais, há que se pensar em como podem os discursos de ordem intelectual contribuir para a efetivação de ações escolares significativas em Arte.

Pode-se dizer que as intenções sociopolíticas têm seu registro na formulação escrita do currículo, a qual indica publicamente quais as aspirações e intenções da prática educativa, a partir de compromissos e acordos que envolveram conflitos, rupturas e ambiguidades. Essa elaboração, porém, nunca terá como resultado a proposta fiel do que foi intencionado, pois sua execução se dá efetivamente no ambiente de cultura escolar, onde os contextos intelectuais extrapolam a sala de aula. O que é possível intuir, portanto, é que o currículo deva ser entendido como promotor de processos exploratórios, um espaço para a atuação argumentativa, criativa e crítica do professor. Ou seja, o discurso do currículo deve ensejar a que cada um possa refletir sobre como pode se dar a construção de conhecimentos na prática escolar por sujeitos sociais que aprendem e que ensinam mutuamente. A reconceituação curricular será feita pelo professor em interação com os alunos, influenciado e influenciando a ambiência escolar.

Inúmeras são as publicações com sugestões de várias linhas teóricas de ensino/aprendizagem de Arte, algumas bastante conservadoras e outras mais contemporâneas. Transformar em ações importantes para a aprendizagem de Arte essas teorias ou relatos de práticas é o que não tem acontecido em grande escala.

Isso pode ser verificado até mesmo em relação a vários dos ex-alunos dos cursos de formação de professores, principalmente os que se inserem em escolas de formato fechado a inovações, que, apesar de terem vivenciado experiências de discussões críticas e terem sido informados de teorias contemporâneas, voltam à sala de aula com o mesmo comportamento de quando eram alunos e sofriam ações pedagógicas que criticavam. Parece que os anos da Graduação não conseguem impactar o suficiente para que suas práticas se modifiquem. O problema é que, dessa maneira, após anos de prática, a

Revista Digital do LAV - Santa Maria - vol. 8, n. 2, p. 5 - 17. - mai./ago. 2015 ISSN 1983 - 7348 http://dx.doi.org/10.5902/1983734819862 
experiência pessoal tende a perpetuar sua atuação e, se isso se mantém, não haverá condições de que mudanças de atitudes sejam possíveis de acontecer em médio prazo.

Ao pensar um currículo contemporâneo, há necessidade de pensar a ambiência escolar, pois não só o currículo de Arte, mas o dos demais componentes curriculares também teriam que sofrer alterações para estarem em dia com o pensamento de teorias inovadoras.

A Física e a Matemática que passaram do modelo de solução única e absoluta e adotaram o modelo estatístico-probabilístico. Biologia serviu de base para o conexionismo, que tem por princípio a construção de conhecimento a partir das relações possíveis entre experiência e vivência em rede, tendo a capacidade de aprender como paradigma de inteligência. Estudos de linguagem consideram que ela não é simplesmente ferramenta para comunicação, mas sim um ambiente intelectual onde grande parte dos processos de pensamento se estruturam e desenvolvem. (DEOUD, 2005) No entanto, não se consegue detectar, na maioria dos currículos, a reverberação dessas teorias no ensino/aprendizagem desses componentes curriculares na educação básica.

As funções de supervisão, que também fazem parte da ambiência escolar, ainda estão no mesmo patamar do século $X X$, pouco colaborando para a reestruturação do espaço escolar como possibilidade de compartilhamento de vivências e experiências de construção de conhecimento. Na maioria das vezes, esses profissionais reforçam posições conservadoras de disciplina e de hierarquia entre os componentes curriculares. Torna-se necessária uma cooperação mais próxima entre os estudos da ciência cognitiva e os estudos específicos das áreas de conhecimento integrados na ambiência escolar, uma vez que um contexto intelectual mais ágil, fluido, amplo e múltiplo promove o entendimento dessa ambiência e tem grande peso no direcionamento das ações educacionais.

\section{Algumas considerações finais}

Tomasello (2003) propõe o conceito de evolução cultural cumulativa, indicando que tradições e artefatos culturais acumulam modificações ao longo do tempo. Segundo o autor, a capacidade de indivíduos compreenderem uns aos outros faz com que se imaginem na "pele mental" dos iguais, propiciando a cognição social que favorece novas

Revista Digital do LAV - Santa Maria - vol. 8, n. 2, p. 5 - 17. - mai./ago. 2015 ISSN 1983 - 7348 http://dx.doi.org/10.5902/1983734819862 
maneiras de aprendizagem cultural. Graças a isso, é possível haver a evolução cultural cumulativa. Ao se inserir mais consistentemente arte a ambiência escolar, isso se refletirá no contexto cultural de maneira mais ampla. A inserção de Arte como área de conhecimento no processo educativo é essencial para que isso aconteça.

Efland (2002) propõe que metáfora e imaginação devam ser integrantes essenciais das metodologias de ensino/aprendizagem em Arte, devido à sua importância cognitiva em todos os campos do conhecimento, e especialmente em Arte. Elas são componentes chaves para inserir os conhecimentos construídos na escola no contexto de vida do estudante. Segundo o autor, a imaginação é uma atividade estruturadora que usa a metáfora para estabelecer conexões significativas, sendo as elaborações metafóricas essencialmente corpóreas.

Em Arte, é necessário que questões de estética, imaginação e metáfora sejam tratadas tanto conceitualmente quanto na imersão artística, como dinâmica cognitiva humana. As experiências culturais cotidianas podem levar à descoberta de qualidades estéticas, porém, somente as experiências do dia a dia não são suficientes para garantir a aprendizagem de Arte em sua plenitude. Inserir plenamente a arte no contexto de vida cultural cumulativa, em fluxos constantes, é o que se espera do processo escolar contemporâneo.

\section{Referências}

BARBOSA, Ana Mae. Arte-Educação no Brasil. São Paulo: Perspectiva, 1978.

BRASIL. Parâmetros Curriculares Nacionais - Arte. Brasília: Secretaria da Educação Básica, 1997.

BULHÕES, Maria Amélia (org.). As novas regras do jogo: o sistema de arte no Brasil. Porto Alegre: Zouk, 2014.

DEOUD, Fernando. Arte: Ambiência Estética, Imaginativa e Metafórica. Dissertação de Mestrado em Artes, EBA/UFMG, 2005.

DEWEY, John, Arte como experiência. São Paulo: Martins Fontes, 2010.

Revista Digital do LAV - Santa Maria - vol. 8, n. 2, p. 5 - 17. - mai./ago. 2015 ISSN 1983 - 7348 http://dx.doi.org/10.5902/1983734819862 
EFLAND, Arthur D. Art and Cognition: integrating the visual arts in the curriculum. New York: Teachers College and National Art Education Association, 2002.

LACERDA, Nilma Gonçalves. Manual de Tapeçaria. Rio de Janeiro: Philobiblion, 1986.

MOREIRA, Antônio Flávio. Currículos e programas no Brasil. Campinas, SP: Papirus, 1995. Coleção Magistério: formação e trabalho pedagógico.

PIMENTEL, Lucia Gouvêa. Ensino/Aprendizagem de Arte e sua pesquisa: possibilidades e desafios. In: ROCHA, M.A.; SOUZA, J.A.M. Fronteiras e alteridade: olhares sobre as artes na contemporaneidade. Belém: PPGARTES-UFPA, 2014.

PIMENTEL, Lucia Gouvêa. Limites em expansão: licenciatura em artes visuais. Belo Horizonte: C/Arte, 1999.

RUPP, Bettina. Da organização de exposições à curadoria: considerações sobre a formação da atividade no país. In: BULHÕES, Maria Amélia (org.). As novas regras do jogo: o sistema de arte no Brasil. Porto Alegre: Zouk, 2014, p.77-104.

SOUZA, J.A.M.; PIMENTEL, L.G. Apresentação. In Anais do $23^{\circ}$ Encontro Anual da ANPAP. Disponível em: http://anpap.org.br/anais/2014/ANAIS/ANAIS.html\# Acesso em: $12 / 01 / 2015$.

TOMASELLO, Michael. Origens Culturais da Aquisição do Conhecimento Humano. São Paulo: Martins Fontes, 2003.

VIVEIROS DE CASTRO, Eduardo. A inconstância da alma selvagem e outros ensaios de antropologia. São Paulo: Cosacnaify, 2002.

\footnotetext{
${ }^{1}$ Professora Titular da Escola de Belas Artes da Universidade Federal de Minas Gerais, Coordenadora Adjunta da área de Artes/Música para o Mestrado Profissional da Coordenação de Aperfeiçoamento de Pessoal de Nível Superior - CAPES e Conselheira do Instituto Arte das Américas. Líder do Grupo de Pesquisas Ensino da Arte e Tecnologias Contemporâneas e participa de grupos de pesquisa em Educação e em Tecnologias. Atua como artista, professora e pesquisadora, com ênfase em Ensino de Arte e em Gravura,
}

Revista Digital do LAV - Santa Maria - vol. 8, n. 2, p. 5 - 17. - mai./ago. 2015 ISSN 1983 - 7348 http://dx.doi.org/10.5902/1983734819862 
atuando principalmente nos seguintes temas: ensino de arte, artes visuais, ensino de arte e tecnologia, arte/educação, formação de professores, cognição imaginativa e gravura. E.mail: luciagpi@gmail.com

Recebido em: 13 de maio de 2015.

Aprovado em 23 de agosto de 2015. 